\title{
Research on the Mode and Pricing of Internet Insurance Based on Precise Poverty Alleviation
}

\author{
Pengbo Yang ${ }^{1}$, Hao Luo ${ }^{2}$, Xinyue $\mathrm{Ma}^{3}$ \\ ${ }^{1,2,3}$ Xidian University, School of Economics and Management, Xi Feng Road, Xinglong Section 266, Xi'an, Shaanxi Province, China
}

\begin{abstract}
In order to realize the ambitious goal of the existing poverty alleviation in 2020, the CPC Central Committee has intensified its efforts to develop poverty alleviation and poverty alleviation. The CIRC has identified agricultural insurance as one of the main directions of the insurance industry to fight the poverty alleviation. This paper attempts to build the operation mode of Internet insurance in precision poverty alleviation and explore the pricing model of Internet insurance. Finally, it puts forward the relevant conclusions and suggestions of government guidance and market operation, which is conducive to the promotion and application of Internet insurance in precision poverty alleviation.
\end{abstract}

Keywords: Internet insurance, Precise poverty alleviation, Government guide, Option pricing

This study was supported by the Fundamental Research Funds for the Central Universities (ID: JB160607)

\section{Introduction}

'Eliminating poverty, improving people's livelihood and realizing common prosperity' is the essence of socialism and an important condition for realizing social stability and harmonious development. In recent years, the CPC Central Committee and the State Council have attached great importance on poverty alleviation and development work.

On November 29, 2015, the CPC Central Committee and the State Council promulgated the Decision on Winning the Poverty Alleviation, formally announcing the implementation of the Poverty Alleviation Strategy, and launched a new round of poverty alleviation and development, to clearly put forward by 2020 that the authority will put more than 70 million poor people out of poverty. In March 2016, the People's Bank of China, the National Development and Reform Commission, the National Security Commission and the Poverty Alleviation Office and other several departments jointly issued the "financial assistance to push the poor implementation of the views of the proposed" to expand the density and depth of agricultural insurance for agricultural insurance coverage in poor areas range.

Agricultural Internet insurance is to promote precision poverty alleviation work in a strong policy initiatives. The insurance is regarded as a tool to achieve a comprehensive well-off which can be used as an important starting point and the formation of a unique and sustainable innovation.

In the background of the vigorous development of Internet finance in China, the technologies such as Internet, social network, cloud computing and large data began to penetrate into the insurance industry, which profoundly affected the operation and development of insurance companies. Internet insurance in the implementation of precision poverty alleviation process, not only plays the role of insurance itself to reduce the risk, but also takes the advantages of the Internet to speed up the pace of solving the problem of poverty in rural areas of China.

\section{Literature review}

At present, the application of option pricing method in the field of insurance mainly focuses on the field of deposit insurance. These studies can be traced back to Merton's (1977) study of deposit insurance, and subsequently Marcus \& Shaked (1984) on the further development of its approach. The philosophers such as Flannery (1991), Pennacchi (2005) and Lee et al. (2015) further incorporate systemic risk into the model and improve the theoretical framework for deposit insurance pricing ${ }^{[1]}$. The latest study by Lee et al. (2015) shows that systemic risk will significantly affect the deposit insurance premium, which is expected to be several times higher than Merton (1977) ${ }^{[2]}$.

In terms of pricing methods, Tuo Guozhu (2012) argues that agricultural insurance system defects gradually reveale that adverse selection and moral hazard are unavoidable ${ }^{[3]}$. When the cost of agricultural insurance is established by commercial insurance system, the cost of reverse selection and moral hazard is taken into the insurance price. Dong Wanlu (2014)shows that the United States a comprehensive agricultural insurance system and a variety of futures hedging methods for the US farmers to provide an effective risk prevention safety net ${ }^{[4]}$. Chen Tingting (2014) studied the pricing of European bullish insurance futures options, and finally deduced the pricing of continuous and geometric average European bullish insurance futures options using the actuarial pricing method ${ }^{[5]}$. Shao Jie (2016)combs the method of determining the premium rate of the weather index ${ }^{[6]}$. At present, the actuarial pricing method is used to calculate the rate.

\section{The statement of the problem}

At present, when it comes to China's insurance about 'three rural' in the development of poverty-stricken areas, there are still several problems as follows.

First, commercial insurance institutions are mostly reluctant to 


\section{International Journal of Science and Research (IJSR) \\ ISSN (Online): 2319-7064}

Index Copernicus Value (2015): 78.96 | Impact Factor (2015): 6.391

enter the field of agricultural insurance, resulting in a single agricultural insurance products, high premiums, limited coverage. As a consequence, many poor areas can not have a chance to get the agricultural insurance services.

Second, government support is not enough, and agricultural insurance development potential is insufficient. Financial support for companies currently offering agricultural insurance is limited to partial premium subsidies and tax incentives, and other policy support is still in desperate need. In the process of laanding the policy of agricultural insurance, there is fraud with excessive subsidies. Supervision is not in place. So farmers in the natural disaster or accident have to bear the loss.

Third, in most of the poverty-stricken areas of our country, farmers have more deep-rooted awareness of the insurance. For insurance companies, the amount is too low, the responsibility is too narrow, the actual risk of the gap is too large, and the role of economic compensation is not obvious.

An important feature of Internet insurance is its low premium. The insured only need a small premium investment to get the appropriate protection. Another important feature of Internet insurance is that the terms are concise and highly subdivided, and no other steps are required except for internet payments. So the Internet insurance in the precision of poverty in the pricing method puts forward higher requirements.

Based on the above analysis, this paper means to construct a general system framework which combines Internet insurance and precision poverty alleviation, and obtains the reasonable pricing of Internet insurance products from Internet insurance products so that it can meet the Internet insurance pricing needs in precision poverty alleviation.

\section{The role of Internet Insurance in Precise Poverty Alleviation}

Accurate poverty alleviation refers to the targeting of poverty alleviation in different poverty-stricken areas, and the situation of different poor farmers. It is a way of the use of scientific and effective procedures for the implementation of accurate identification of poverty-stricken people, precise help, and accurate management of poverty alleviation, which can improve the relevance and effectiveness of poverty alleviation. Precise poverty alleviation should be accurate, requiring the use of policies, funds, projects and other poverty alleviation resources. The purpose of the insurance industry is to support the poor timely help, and its essence is to help each other through economic compensation to reflect its security value.

Most of the poor people living in rural areas, they consider agricultural production as the main source of livelihood, and the characteristics of agricultural production determine their vulnerability to natural risks and market risks.

Agricultural insurance can prevent agricultural risks and compensate for the loss of agricultural disasters, so that poor farmers receive timely payment after the disaster, contribute to the resumption of production, improve the reproduction capacity, protect the income of farmers, and effectively reduce the farmers caused by poverty, which are consistent with the goal of precision poverty alleviation.

Precision poverty alleviation based on Internet agriculture insurance can make full use of both government and the market. It can provide more accurate allocation of poverty alleviation resources. On the one hand, with the help of agricultural insurance, government can lead poor families to carry out cultivation or farming to provide a guarantee of poverty alleviation. Especially the new agricultural insurance products, they do well in avoiding the risk on the basis of the increase in output and product price stability. On the other hand, agricultural insurance can also solve the problem of shortage of funds in the process of precision poverty alleviation.It can play their own direct financing and credit enhancement function, and effectively solve the problem of the demand of poor peasants. In the work of precision poverty alleviation, agricultural insurance plays an important role as stabilizer and safety net, which is an important tool for precision poverty alleviation.

\section{The operating mechanism of agricultural Internet insurance}

Chinese agricultural insurance precision poverty alleviation should always implement the government guidance with market operation concept of operation, as shown in Figure 1.

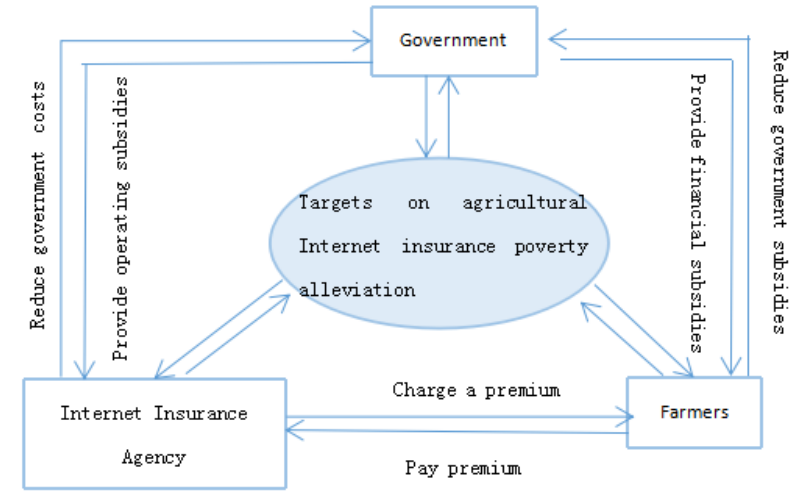

Figure1: The operating mechanism of Internet agricultural insurance

Government guidance mechanism is through the central and local government policy support, incentive and restraint of agricultural insurance market operation, so as to guide the agricultural insurance market efficient operation and balanced development. The central government mainly improve agricultural insurance business policy support system for the agricultural insurance market management to provide a good policy guidance and system protection.

First, continue to establish the relevant agricultural security system, and regulate the main behavior of agricultural insurance market to ensure the smooth implementation of agricultural insurance. Second, provide farmers with certain agricultural insurance financial subsidies to expand the coverage of agricultural insurance premiums to promote agricultural insurance demand growth. Third, provide a certain degree of business subsidies to all levels of commercial insurance companies and organizations. The local government 


\section{International Journal of Science and Research (IJSR) \\ ISSN (Online): 2319-7064}

Index Copernicus Value (2015): 78.96 | Impact Factor (2015): 6.391

is the effective implementer of the central policy and promotes the smooth implementation of the local agricultural insurance business.

\section{Internet insurance pricing model}

In the option pricing analysis, we make the following assumptions: the expectations of the insurance company for the total amount of compensation for different agricultural losses are equal each year. That is to say, with high agricultural loss rate or low agricultural loss rate data, the results will be consistent.

For an agricultural insurance contract with a guaranteed period $\mathrm{T}$, the peasants pay the same amount of premium $\mathrm{X}$ (agricultural insurance price) at the beginning of each period, which are paid at the end of a period according to their agricultural losses. Such an insurance contract can be equivalently seen as a structured option product consisting of a T-bullish bargaining option for the agricultural loss probability sequence $\mathrm{P}$. This article assumes that the peasants spend at the beginning of each period to buy a bullish barrier option at the beginning of the period

Only when $\mathrm{P}$ is 1 , the insured has received the agreed premium and all refunds paid. When $\mathrm{P}$ is zero, the pay is zero, either. At the end of the period $t$, the single bullish barrier option payment can be written as follows.

$$
\mathrm{C}_{t}=\left\{\begin{array}{l}
M+t X, P=1 \\
0, P=0
\end{array}\right.
$$

$\mathrm{M}$ is the agreed insured amount, and $\mathrm{X}$ is the one-time premium determined by the insurance contract. In order to determine the value of the structured option product, this article from the perspective of the insurance company to further analysis. The total number of insured persons who assumed the purchase of agricultural insurance insurance to the insurance company was 100000 and the risk-free rate was r.

For insurance companies, the cash inflow generated during the duration of the sale of structured option products is PVCI.

$$
P V C I=\sum_{t=1}^{T} \frac{\left(100000-\sum_{i=0}^{t-1} P N_{i}\right) X}{(1+r)^{t-1}}
$$

All cash outflow discount generated during the duration period is PVCO.

$$
P V C O=\sum_{t=1}^{T} \frac{(M+t X) P N_{t}}{(1+r)^{t}}
$$

Under the no-arbitrage principle, it is determined that the structured option product price $\mathrm{X}$ is the solution of the following equation.

$$
\mathrm{PVCI}=\mathrm{PVCO}
$$

$$
\sum_{t=1}^{T} \frac{\left(100000-\sum_{i=0}^{t-1} P N_{i}\right) X}{(1+r)^{t-1}}=\sum_{t=1}^{T} \frac{(M+t X) P N_{t}}{(1+r)^{t}}
$$

$\mathrm{M}$ and $\mathrm{T}$ are the specific values specified in the
contract.PNt is only historical data. Therefore, it is necessary to use Monte Carlo method to carry out numerical simulation based on PNt's historical data to obtain the predicted value of PNt throughout the guarantee period. After a large number of simulations, the mean of X can be approximated as the price of structured option products.

Assume that the number of agricultural losses per year in every 100,000 insured farmers is subject to obey geometric Brownian movement. The variable value of PNt per unit time can then be defined as follows:

$$
\begin{gathered}
d P N_{t}=\mu P N_{t} d t-\delta P N_{t} d w \\
\Delta P N_{t}=P N_{t+\Delta t}-P N_{t}=\mu P N_{t} \Delta t+\delta P N_{t} \sqrt{\Delta t} \varepsilon_{t} \\
P N_{t+1}=P N_{t}+\mu P N_{t}+\delta P N_{t} \varepsilon_{t}
\end{gathered}
$$

In the process of numerical simulation, $\mathrm{T}(6,12,24,36$ months) and different agricultural insurance premiums $\mathrm{T}(300,500$ yuan) are selected for different duration periods. Simulations are set for different combinations of $T$ and $M$ respectively. When the number of $\mathrm{n}$ is 3000 , each simulation is predicted a complete duration of a total of $\mathrm{T}$ occurred in the loss of agricultural products, the number of farmers is PNt.

Then the simulated PNt sequence is substituted into equation (5) to calculate the price of the structured option product $X$ in the agricultural insurance, which can be approximated as the price of the agricultural insurance.

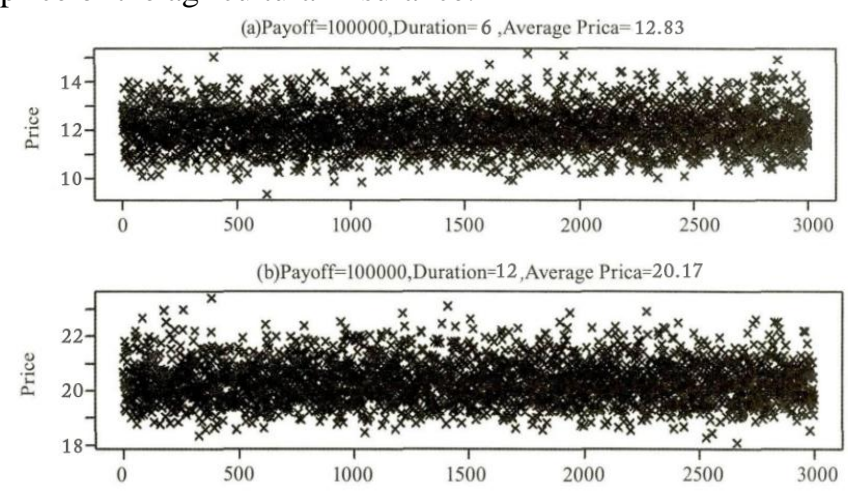

Figure2: Simulation based on different months

Because of the difference between the specific agricultural insurance product terms (insured, insured area, etc.) and the basic assumptions of this paper, the final price of the product and the calculated results may not be exactly equal. At the same time, the insurance company's product pricing strategy will also affect the actual price of Internet insurance products.

\section{Conclusion and Suggestion}

In this paper, the agricultural insurance is taken as an example to study the consumer Internet insurance option structure. As the agricultural insurance is the structure of these types of insurance, the actual application only needs to modify the parameters of the framework, and variables can be modified slightly to other consumer Internet insurance pricing.

Internet insurance industry to implement the "precision poverty alleviation" should identify the main focus, fully 
reflect the insurance poverty alleviation and help the poor.

First, establish the multi-level agricultural insurance system. The government should promote and guide the existing insurance branches for agricultural insurance business. For professional agricultural insurance companies, they set up institutions, expand their business, and gradually form a multi-form, multi-channel agricultural insurance system.

Second, construct the agricultural risk dispersion mechanism. By the financial and agricultural insurance business agencies jointly funded the establishment of agricultural disaster risk insurance fund, in the event of catastrophe risk situation, the insurance company can be compensated from the risk mutual aid fund. It can balance the financial and insurance companies.

At the same time, agricultural Internet insurance business should be based on local economic development level, the degree of development of agricultural insurance and agricultural insurance policy objectives.

\section{References}

[1] Lee S C.Lin C T. Tsai M S.The pricing of deposit insurance in the presence of systematic risk[J].Journal of Banking \& Finance, 2015,51,1-11.

[2] Merton.Schwartz E.The pricing of equity - linked life insurance policies with an asset value guarantee[J].Journal of Financial Economics,1977,3(3) : 195-213.

[3] Tuo Guozhu i, Wang Wenping, Huang Kai.R \& D investment decision-making theory based on option pricing theory [J] .Journal of Scientific Research Management, 2012, (4): 45- 49.

[4] Dong Wanlu, Li Hongen. Method of Real Option for Land Pricing: A Case Study of China 's Land Market [J]. World Economy, 2014,(8) 63-72.

[5] Chen Tingting. Research on the Efficiency of Policy based Agricultural Insurance in China - Based on Transaction Cost point of view [J]. Insurance research. 2014 (11)58-60.

[6] Shao Jie, Pu Yong, etc. Technical innovation strategy investment real options method [J]. Journal of Management Science, 2016,7 (1): 88-96.

\section{Author Profile}

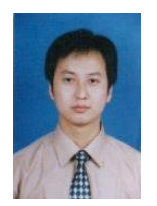

PengBo Yang works as an associate professor in school of Economics and Management, XIDIAN University. His specialization lies in consumer finance and behavioral finance.

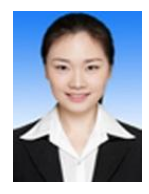

Hao Luo is now pursuing Master degree since 2016 under the guidance of Prof. Jiang. Her specialization area is Fiance.

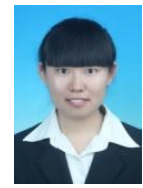

Xinyue Ma is now pursuing Master degree since 2016 under the guidance of Prof. Jiang. Her specialization area is Fiance. 